\title{
The Effect of Density on the Delicate Balance between Structural Requirements and Environmental Issues for AAC Blocks: An Experimental Investigation
}

\author{
Daniele Ferretti (D) and Elena Michelini *(D)
}

check for

updates

Citation: Ferretti, D.; Michelini, E. The Effect of Density on the Delicate Balance between Structural

Requirements and Environmental

Issues for AAC Blocks: An

Experimental Investigation.

Sustainability 2021, 13, 13186.

https://doi.org/10.3390/su132313186

Academic Editor: Castorina

Silva Vieira

Received: 10 November 2021

Accepted: 26 November 2021

Published: 28 November 2021

Publisher's Note: MDPI stays neutral with regard to jurisdictional claims in published maps and institutional affiliations.

Copyright: (c) 2021 by the authors. Licensee MDPI, Basel, Switzerland. This article is an open access article distributed under the terms and conditions of the Creative Commons Attribution (CC BY) license (https:// creativecommons.org/licenses/by/ $4.0 /)$.
Department of Engineering and Architecture, University of Parma, 43124 Parma, Italy; daniele.ferretti@unipr.it

* Correspondence: elena.michelini@unipr.it

\begin{abstract}
Among other construction materials, Autoclaved Aerated Concrete (AAC) offers several advantages to face the pressing need to build more sustainable and energy-efficient buildings. From the building side, the low thermal conductivity of AAC allows the realization of energyefficient building envelopes, with interesting savings in terms of heating and cooling processes. The equilibrium between structural performances (related to safety issues) and energy efficiency requirements is, however, very delicate since it is strictly related to the search for an "optimum" material density. Within this context, this work discusses the results of wide experimental research, showing the dependency of the most important mechanical properties (compressive strength, elastic modulus, flexural strength and fracture energy) from density, as well as the corresponding variation in thermal conductivity. In order to identify the better compromise solution, a sort of eco-mechanical index is also defined. The big challenge for future researches will be the improvement of this ecomechanical index by working on pore structure and pore distribution within the material without significantly reducing the density and/or by improving the strength of the skeleton material.
\end{abstract}

Keywords: autoclaved aerated concrete; experimental tests; dry density; compressive strength; flexural strength; elastic modulus; fracture energy; thermal conductivity; eco-mechanical index; green building development

\section{Introduction}

In the last years, green buildings and sustainable solutions for the construction sector have drawn the attention of designers and manufacturers, as well as of the scientific community, due to the increasing problems regarding pollution and climate changes that modern society is experiencing [1]. It is well known that the construction industry produces a large number of global carbon emissions at all its stages: from materials' production and transportation to the building erection stage and waste management until dismantlement. A large part of carbon emissions is, however, related to the normal functioning of buildings in terms of energy consumption for indoor heating and cooling. It was estimated that the need to ensure adequate thermal comfort to building occupants causes the consumption of approximately 30-40\% of global energy [2,3] and is responsible for half of the European Union final energy consumption (FEC), making it the biggest energy end-use sector. For this reason, the European 2012 Energy Efficiency Directive [4] put building energy efficiency to the fore, pushing for renovation strategies for the existing building stock and for future procurement of energy-efficient buildings. The proposal for a new directive on energy efficiency was recently put forward by the European Commission in July 2021 as part of the package "Delivering on the European Green Deal". This document gives even more emphasis to the crucial role played by heating and cooling in the Union's ambition to reach a carbon-neutral economy by 2050 [5]. Within this context, the need to enhance building insulation carries out the lion's share. For new constructions, energy efficiency improvement takes place as a result of the enforced application of stringent building codes 
and of the adoption of passive, active or combined measures that will help to achieve the target of near-zero energy buildings (NZEBs) [6,7]. In particular, passive measures aim at minimizing the energy demand by exploiting the design and the properties of the building envelope, basically to ensure heat protection. Since walls normally represent the largest portion of the building envelope, the first and more obvious strategy to achieve this goal relies on the choice of construction materials with a high thermal resistance (that is to say, with good thermal insulation properties). In this way, it is possible to minimize the heat flow due to temperature differences between the building interior and the external environment during all seasons. A quite common solution, which is particularly suited for the retrofit of existing buildings, is represented by the use of external thermal insulation composite systems (ETICS). These systems are formed by thermoinsulation plates fixed onto the substrate with the use of glue and special anchors and covered by an external coating [8]. Another possible strategy is to use new materials with good insulation properties and adequate bearing capacity to realize "single layer" walls, without the need to resort to additional external thermal insulation systems or limiting the thickness of additional layers [2,9]. One of these "environmentally friendly" materials is autoclaved aerated concrete (AAC), which is typically made of fine silica aggregates, cement, lime, gypsum, water and an expanding agent (the most common is aluminum powder). Thanks to the addition of the expanding agent, during the molding process, the air is entrapped artificially in the admixture, with a consequent increase in material porosity and a significant reduction in density $[10,11]$. The material is then strengthened through autoclave curing at high temperature and pressure, which leads to the formation of calcium silicate hydrate phases, mainly a stable form of tobermorite. In virtue of its porous structure, AAC offers excellent thermal performance, which makes it a good insulating material. Other interesting features are related to the lighter weight, the possible savings in material and the potential for large-scale utilization of industrial by-products in the manufacturing process. For these reasons, there is considerable interest from the building sector to also exploit AAC as a structural material for the realization of masonry blocks for bearing walls [12-21]. With respect to other systems (such as concrete blocks or red clay bricks), the use of AAC bearing masonry for residential buildings can offer more energy savings already without the application of additional insulation layers by decreasing the cooling energy by $12 \%$ and the total energy consumption by about $7 \%[20,22]$. This positive behavior can be attributable to the fact that AAC masonry prevents thermal bridges, which are often associated with conventional walls, and creates an airtight building envelope, reducing air leakages. However, more importantly, the energy savings related to the use of AAC masonry are strictly related to the added value of thermal mass and low thermal conductivity of the raw material [20,23-25].

The reduction in thermal conductivity is basically achieved by reducing the dry density of the material $[26,27]$, but this leads to a simultaneous reduction in the compressive strength and in the other mechanical properties of the material. For this reason, depending on the final use of AAC blocks (i.e., load-bearing masonry in seismic or not seismic-prone zones, claddings or internal partitions-without any bearing function), an "optimum" value of dry density should be achieved during the production process to reach a good compromise between thermal and mechanical performances [28]. Although this concept seems quite obvious for load-bearing masonry elements, which should respect minimum values of compressive strength according to design standards (e.g., [29] for the design in the seismic-prone zone), it should be kept in mind also for infill masonry. It is indeed well known that, in framed structures, the load-bearing function is entrusted to beams and columns; however, the mechanical properties of masonry infill panels should be adequate to avoid undesirable early failures. For this reason, a minimum compressive (and also tensile) strength should be guaranteed in order to prevent local compression crushing at the corners, as well as premature cracking of the wall [30]. Despite a large number of studies available in the literature on the mechanical characterization of AAC blocks, only a few of them [31-36] discuss the dependency of the mechanical properties from density by 
analyzing experimental results relative to the same production (i.e., referred to the same raw materials and autoclaving conditions, which are known to be the intrinsic factors with a stronger influence on AAC properties [37-40]). Most published works are referred to the characterization of a specific product (with a given density), and this makes it difficult to put the available data together to derive a general trend because of the different raw materials in the admixture and the different conditions followed for the thermal treatment. Moreover, most of the available studies are mainly focused on compressive strength, while other properties are not deeply investigated.

This work discusses the results of a wide experimental program carried out on AAC masonry blocks characterized by four different densities, approximately ranging from $300 \mathrm{~kg} / \mathrm{m}^{3}$ to $580 \mathrm{~kg} / \mathrm{m}^{3}$, which represent the most common values available on the European market. The main material properties (compressive strength, flexural strength, fracture energy, elastic modulus) were determined as a function of dry material density. Special attention was also paid to the determination of fracture energy and to its variation with density due to the limited experimental data available in the literature $[39,41-44]$. Despite being less investigated than the tensile strength, fracture energy is indeed an important parameter that governs crack propagation and influences material ductility. For this reason, it is required as an input parameter when performing finite element (FE) analyses on AAC masonry for the calibration of a proper cohesive law for blocks. For a given density, experimental tests were also repeated for different moisture contents to highlight the effect of water content entrapped within pores on the mechanical properties. The effectiveness of analytical relations given by RILEM Recommended Practice [28] and other expressions available in the technical literature (i.e., [31,45-47]) was also verified. Comparisons highlight some critical issues in the formulation of analytical relations with general applicability. It was found that RILEM suggestions are appropriate for the considered AAC productions, at least for densities greater than $400 \mathrm{~kg} / \mathrm{m}^{3}$.

Finally, the variation in mechanical properties with density was also related to the corresponding variation in thermal conductivity to find a sort of eco-mechanical index for each investigated product [48].

\section{Materials and Methods}

In this study, AAC specimens were derived from commercially available masonry blocks, with nominal dimensions equal to $600 \times 250 \times 300 \mathrm{~mm}$. The blocks were directly provided by the manufacturer and were characterized by four different nominal densities, indicated in the following as D1 $=300 \pm 50 \mathrm{~kg} / \mathrm{m}^{3}, \mathrm{D} 2=350 \pm 50 \mathrm{~kg} / \mathrm{m}^{3}$, $\mathrm{D} 3=480 \pm 50 \mathrm{~kg} / \mathrm{m}^{3}$ and D4 $=580 \pm 50 \mathrm{~kg} / \mathrm{m}^{3}$. These blocks are those routinely used in Italy and in most European countries for the realization of high insulating infills in framed structures (D1 and D2 class) and of load-bearing masonry in non-seismic and seismic-prone zones (D3 and D4 class), respectively. The typical raw materials used for all the examined density classes were ordinary Portland cement, lime, gypsum, high quartz sand as fine aggregate, and aluminum powder as blowing agent. The bulk density was mainly changed by altering material porosity (basically artificial air pores), which was in turn mainly controlled by the dosage of the expanding agent [40]. All AAC products were autoclaved at $180^{\circ} \mathrm{C}$ and cured at 12 bars pressure in the autoclave chamber for $11 \mathrm{~h}$. This treatment allowed to impart strength, dimensional stability and other properties to the hardened final product, thanks to the formation of hydrothermally synthesized crystalline calcium-silicate-hydrates.

A detailed literature survey shows that a general agreement about the size and shape of specimens to be used for the mechanical characterization of AAC units has not been reached yet. In previous work, the authors proved that different specimen sampling might lead to a non-negligible change in strength values [42]. A general overview of the performed tests and of the relevant standards and procedures adopted in this experimental program is reported in Table 1 . All the tests were repeated for the four examined density classes, except for those related to the determination of the elastic modulus. The latter was 
indeed simply derived indirectly for all the considered cases by simply elaborating the data coming from compression tests. More accurate results were obtained from specific tests on core samples, which were, however, carried out for two density classes only (i.e., D1 for non-load bearing masonry and D3 for load-bearing ones). Compressive and flexural tests, as well as fracture energy tests, were also replicated for a given density value (equal to $350 \mathrm{~kg} / \mathrm{m}^{3}$, class D2) by varying the moisture content, to investigate the influence of specimen curing before test execution. Moreover, the dependency of compressive strength from preliminary treatments used for smoothening specimen surfaces was also studied, as better explained in the following sections.

Table 1. Overview of the tests performed during the experimental campaign and relevant standards.

\begin{tabular}{cc}
\hline Test & Standard \\
\hline Bulk density & EN 772-13:2002 ${ }^{\mathrm{a}}$ \\
Compressive strength & EN 772-1:2015 ${ }^{\mathrm{b}}$ \\
Flexural strength (MOR) & EN 1351:1997 \\
Fracture energy & JCI-S-001:2003 ${ }^{\mathrm{d}}$ \\
Elastic modulus & ${\text { Rilem Recommended Practice: } 1993^{\mathrm{e}}}$
\end{tabular}

a See [49]. ${ }^{\text {b }}$ See [50]. ${ }^{\mathrm{c}}$ See [51]. ${ }^{\mathrm{d}}$ See [52]. ${ }^{\mathrm{e}}$ See [28].

\subsection{Specimen Sampling}

The sampling schemes adopted in this work are outlined in Figures 1 and 2. As can be seen from Figure 1, 6 cubic samples and 3 prismatic samples were cut from the top, middle and bottom of each AAC block by means of a diamond blade cutter. Three cubic samples with an edge length of $100 \mathrm{~mm}$ were used for the determination of material bulk density, while the other 3 twin specimens were destined for compression tests. Prismatic samples for bending tests were characterized by a square basis with an edge length of $50 \mathrm{~mm}$ and had a total span of $200 \mathrm{~mm}$. For each investigated parameter (density class, moisture content, surface treatment), the sampling was repeated on 6 blocks, according to Tables 2 and 3. In some cases, additional cubes were realized and tested only in compression $(12 \times 3$, instead of $6 \times 3$ ) to evaluate the effect of samples' numerousness on average strength values.

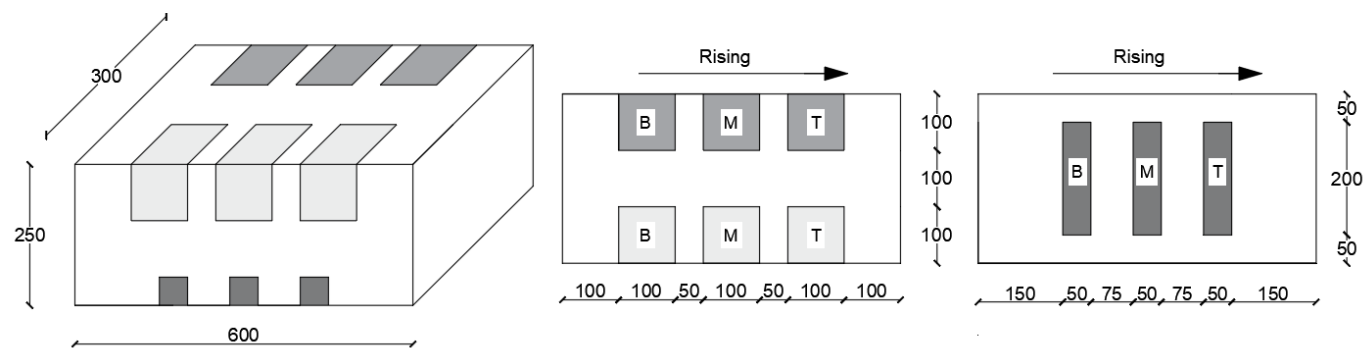

Figure 1. Sampling scheme adopted for the determination of bulk density, compressive strength and flexural strength (dimensions in $\mathrm{mm}$ ).
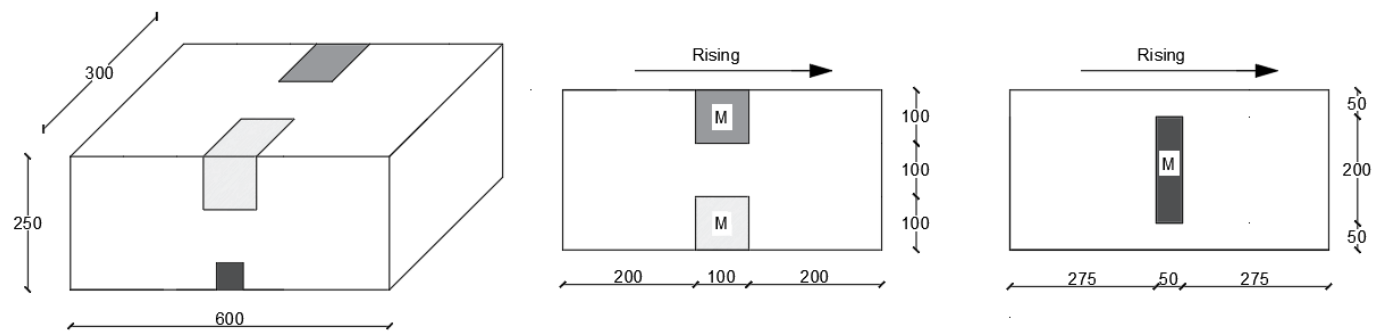

Figure 2. Sampling scheme adopted for fracture energy tests. Twin cubes were also extracted from each block for the determination of bulk density and compressive strength (dimensions in $\mathrm{mm}$ ). 
Table 2. Plan of compressive tests on AAC cubes.

\begin{tabular}{cccc}
\hline Density Class & Moisture Content (\%) & $\begin{array}{c}\text { Preliminary Surface } \\
\text { Treatment }\end{array}$ & Number of Specimens \\
\hline D1 & $6 \%$ & None/sandpaper & $6 \times 3$ \\
& $0 \%$ & None/sandpaper & $12 \times 3$ \\
& $0 \%$ & Surface grinding & $6 \times 3$ \\
D2 & $0 \%$ & Cardboard & $6 \times 3$ \\
& $6 \%$ & None/sandpaper & $12 \times 3$ \\
& $15 \%$ & None/sandpaper & $6 \times 3$ \\
D3 & $20-30 \% 1$ & None/sandpaper & $6 \times 3$ \\
D4 & $6 \%$ & None/sandpaper & $6 \times 3$ \\
& $6 \%$ & None/sandpaper & $6 \times 3$ \\
& Total= & & 198 \\
\hline
\end{tabular}

${ }^{1}$ Moisture content at the delivery to the laboratory.

Table 3. Plan of bending and fracture energy tests on AAC prismatic samples.

\begin{tabular}{|c|c|c|c|c|}
\hline Test & Density Class & Moisture Content (\%) & $\begin{array}{c}\text { Preliminary Surface } \\
\text { Treatment }\end{array}$ & $\begin{array}{l}\text { Number of } \\
\text { Specimens }\end{array}$ \\
\hline \multirow{8}{*}{$\begin{array}{l}\text { Bending } \\
\text { tests }\end{array}$} & \multirow[t]{2}{*}{ D1 } & $6 \%$ & None/sandpaper & $6 \times 3$ \\
\hline & & $0 \%$ & None/sandpaper & $6 \times 3$ \\
\hline & \multirow{3}{*}{ D2 } & $6 \%$ & None/sandpaper & $6 \times 3$ \\
\hline & & $15 \%$ & None/sandpaper & $6 \times 3$ \\
\hline & & $20-30 \%{ }^{1}$ & None/sandpaper & $6 \times 3$ \\
\hline & D3 & $6 \%$ & None/sandpaper & $6 \times 3$ \\
\hline & \multirow{2}{*}{ D4 } & $6 \%$ & None/sandpaper & $6 \times 3$ \\
\hline & & Total $=$ & & 126 \\
\hline \multirow{8}{*}{$\begin{array}{c}\text { Fracture } \\
\text { energy } \\
\text { tests }\end{array}$} & \multirow[t]{2}{*}{ D1 } & $6 \%$ & None/sandpaper & $3 \times 1$ \\
\hline & & $0 \%$ & None/sandpaper & $3 \times 1$ \\
\hline & \multirow{3}{*}{ D2 } & $6 \%$ & None/sandpaper & $3 \times 1$ \\
\hline & & $15 \%$ & None/sandpaper & $3 \times 1$ \\
\hline & & $20-30 \%{ }^{1}$ & None/sandpaper & $3 \times 1$ \\
\hline & D3 & $6 \%$ & None/sandpaper & $3 \times 1$ \\
\hline & \multirow[t]{2}{*}{ D4 } & $6 \%$ & None/sandpaper & $3 \times 1$ \\
\hline & & Total $=$ & & 21 \\
\hline
\end{tabular}

${ }^{1}$ Moisture content at the delivery to the laboratory.

Regarding the determination of fracture energy, the reference method suggested for AAC elements by RILEM recommendations [28] consists of wedge-splitting tests on notched specimens. However, the execution of this type of test is quite complex and requires a completely different setup with respect to that used for bending tests. According to previous findings [42,44], three-point bending tests on notched beams, which represent the standard method to determine fracture energy in the case of mortar and concrete, can also be successfully extended to AAC. Therefore, in this work, it was decided to follow this last approach and to use prismatic specimens with the same geometry as those tested in bending. In order to reduce the number of tests, a different sampling scheme was adopted, according to Figure 2. In this case, only one prismatic sample (together with two twin cubes for the determination of density and compressive strength) was extracted from the middle of each block for a total of 3 blocks for each investigated density class and moisture content, as shown in Table 3.

Sampling operations were performed at the production plant; after their delivery at the laboratory, all the specimens were preliminarily blown with compressed air to remove dust (deriving from cutting operations) from the surfaces.

The elastic modulus in compression was measured on cores extracted at the laboratory from the middle part of the blocks. A total of three cores with a diameter of $100 \mathrm{~mm}$ and a height of $300 \mathrm{~mm}$ were extracted for the two examined density classes (D1 and D3). 
A general overview of the performed tests is provided in Tables 2 and 3 . All the tests were carried out at the Laboratory of Materials and Structures of the University of Parma.

\subsection{Determination of Physical Parameters: Bulk Density and Moisture Content}

As shown in Figures 1 and 2, bulk density was determined on cubic specimens. Following [49], specimens were dried in a ventilated oven at the temperature of $105 \pm 5{ }^{\circ} \mathrm{C}$ until a constant mass was attained. The constant mass condition was assumed to be reached when there were no variations between two subsequent weightings, with no less than a $24 \mathrm{~h}$ interval. Bulk density was then derived from the ratio between the oven-dried mass and the volume of the cubic sample. Moisture content was also evaluated as the ratio between the loss of mass during drying and the corresponding oven-dried mass, expressed as a percentage.

\subsection{Compression Tests}

Compression tests were organized into three main steps. The first part of the research aimed at investigating the influence of bulk density on the compressive strength; for this reason, all the specimens underwent the same surface treatment before testing and were subjected to the same curing conditions. Parallelism and flatness requirements of cubic samples were preliminarily checked, and in the case that they were not satisfied, sample surfaces were simply smoothed with sandpaper (Figure 3a). Among the different curing methods allowed by the applied standard code [50], conditioning to $6 \pm 2 \%$ moisture content was chosen herein. It should be reminded that AAC contains moisture from the manufacturing process and that the moisture content of the blocks at the time of delivery to the laboratory/building site usually ranges between 20 and $30 \%$ by weight. Conditioning to $6 \%$ moisture content is an interesting possibility since it corresponds to the equilibrium condition with the surrounding environment normally reached in external construction after one or two years from building erection (this value may further decrease in time up to about 3\%, [53]). Moreover, unlike other allowable curing options, conditioning to $6 \%$ moisture content does not require the application of a correction factor to the experimental value of compressive strength. In order to achieve this moisture content, specimens were preliminarily dried at a temperature not exceeding $50{ }^{\circ} \mathrm{C}$ until their mass was equal to the dry mass multiplied by 1.06. The specimens were then stored at room temperature for at least $5 \mathrm{~h}$ before testing.

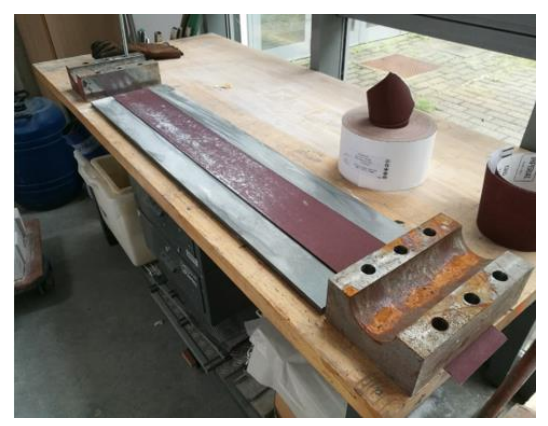

(a)

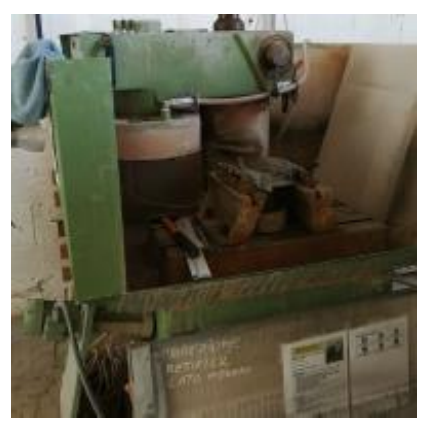

(b)

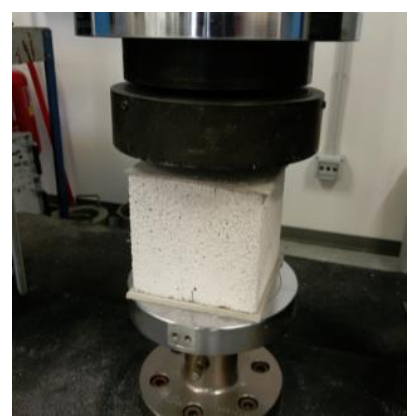

(c)

Figure 3. Possible surface treatments analyzed in this work: (a) none/grinding with sandpaper; (b) wet surface grinding; (c) thin cardboard layer between the specimen and the loading apparatus.

The second step of the work aimed at investigating the dependency of compressive strength from moisture content by keeping other parameters fixed, which is preliminary surface treatment (none/sandpaper, as explained before) and density class (D2 = 350 kg/m ${ }^{3}$ ). In addition to the "reference" moisture value of $6 \%$, the following moisture contents were also studied: $0 \%, 15 \%$ and an upper limit equal to the moisture content of the samples at the time of their delivery to the laboratory, which ranged between $20 \%$ and $30 \%$. According 
to EN 772-1 [50], conditioning to the oven-dry condition ( $0 \%$ moisture content) can be achieved by following two alternative procedures, characterized by different temperature values during the preliminary thermal treatment. In this work, specimens were dried at $70 \pm 5{ }^{\circ} \mathrm{C}$ to constant mass and then stored at ambient conditions until thermal equilibrium was attained. Fifteen percent moisture content was instead achieved by following the same thermal treatment already discussed for conditioning to $6 \%$ moisture content.

Finally, for a given density class (D2 $=350 \mathrm{~kg} / \mathrm{m}^{3}$ ) and a given moisture content $(0 \%)$, the dependency of compressive strength from surface treatment before testing was also studied. To this aim, two additional methods were considered: wet surface grinding (Figure $3 b$ ) and the interposition of a thin cardboard layer between the press platens and the specimen surfaces during test execution (Figure 3c). This latter technique is not permitted from EN 772-1 [50], but it may be a topic of interest among scholars because it represents a quite common method adopted in research works to apply a uniform load during compression tests.

All compression tests were carried out by using an Instron 5882 press working under loading control. The loading rate was set equal to $0.05 \mathrm{MPa} / \mathrm{s}$, which is a typical value for masonry elements with an expected compressive strength lower than $10 \mathrm{MPa}$ [50]. Loading was applied perpendicular to the direction of the rise of the AAC green cake.

\subsection{Bending Tests}

Flexural tensile strength was experimentally determined from three-point bending tests on prismatic samples; the geometry is shown in Figure 1. According to EN 1351, Appendix A in [51], tests were carried out over a net span of $150 \mathrm{~mm}$, and the load was applied at a constant force-controlled rate of $10 \mathrm{~N} / \mathrm{s}$ until failure. The test setup is shown in Figure 4a. An Instron 8862 press was used to the scope.

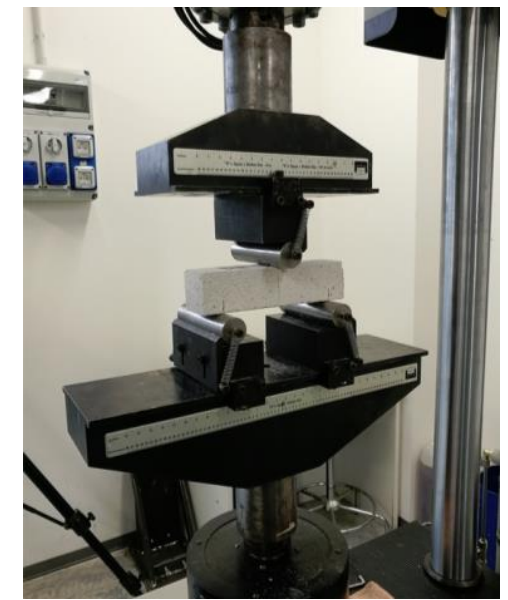

(a)

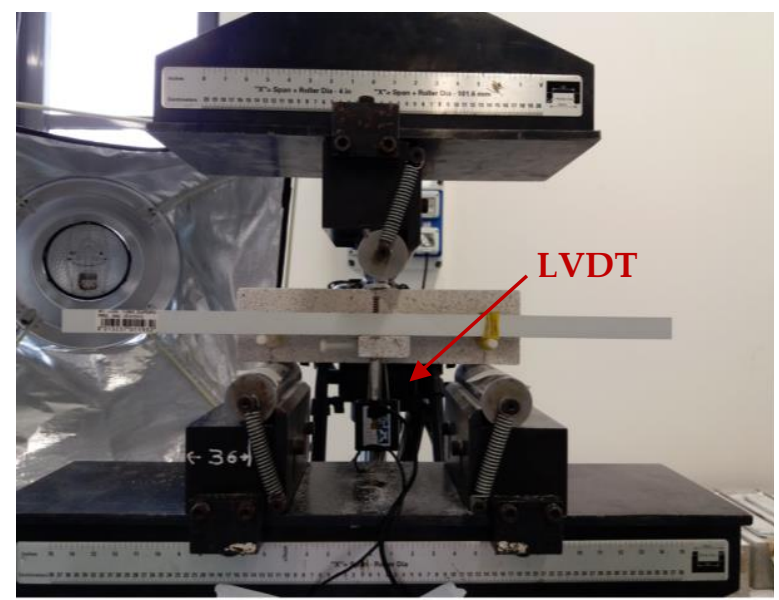

(b)

Figure 4. General overview of the experimental setup: (a) bending tests; (b) fracture energy tests.

Similar to compression tests, the first set of bending tests was carried out on specimens characterized by the same surface treatment (none/sandpaper) and the same moisture content at the time of testing $(6 \%)$ by only varying the density class. A second test series was instead focused on the effect of moisture variation, keeping the surface treatment (none/sandpaper) and the density class (D2) unchanged, as shown in Table 3.

\subsection{Fracture Energy Tests}

Due to the lack of specific rules for the determination of fracture energy in AAC elements by means of three-point bending tests, the Japanese Standard JCI-S-001 [52], which refers to standard concrete, was followed in this work. In this way, it was possible to adopt the same setup already discussed for bending tests with two main changes: a 
notch was made in the central part of the bottom edge of each specimen to guide the crack formation, and tests were carried out under Crack Mouth Opening Displacement (CMOD) control instead of loading control, with a strain rate equal to $1 \mu \mathrm{m} / \mathrm{min}$ [42]. A clip gauge was fixed to the mouth of the notch in order to control and measure crack opening during the test. Specimens were also equipped with a Linear Variable Displacement Transducer (LVDT) to record the evolution of midspan deflection $\delta$ until specimen failure. This LVDT was applied on a specific device fixed onto supports (Figure 4b). A sketch of the experimental setup is shown in Figure 5a.

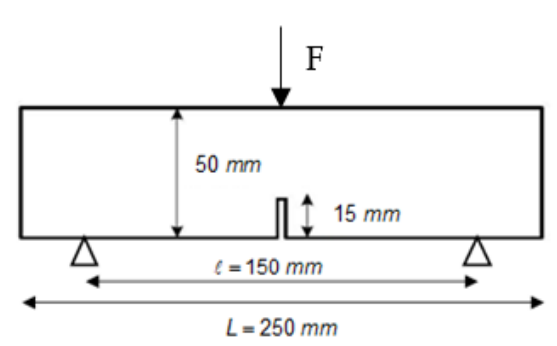

(a)

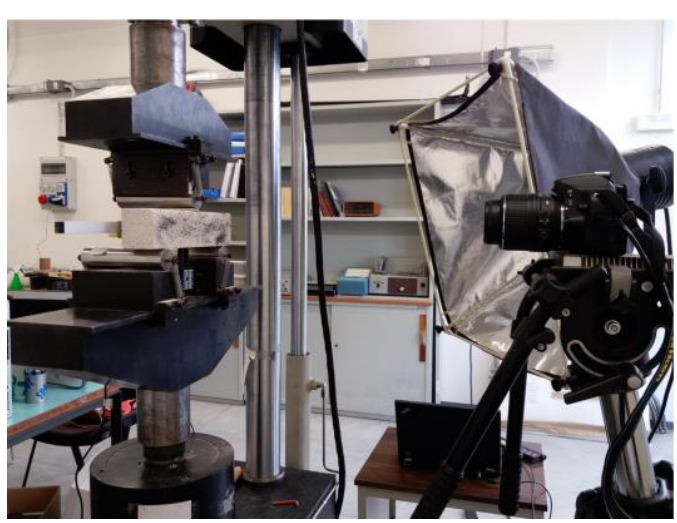

(b)

Figure 5. Fracture energy tests: (a) sketch of the specimen geometry and test setup; (b) DIC setup.

Digital Image Correlation (DIC) was used to complete measurement acquisition in terms of displacements, strains and crack pattern (Figure 5b). As known, in recent years, DIC has become a widespread technique for material characterization, above all when the behavior is affected by cracking occurrence, as in cement-based matrices. In order to apply this method, a speckle pattern (formed by randomly distributed black dots over a white background) was first realized on one side of the specimen by means of spraypainting. A high-resolution camera (Nikon D5100) placed on a stiff frame was used for image acquisition at a constant time interval of $5 \mathrm{~s}$. Image post-processing was performed by means of software Ncorr [54], working under a Matlab environment. In this way, it was possible to derive midspan deflection to be compared with that directly measured by LVDT.

The determination of fracture energy was carried out according to two different approaches. First of all, the relation suggested by the applied standard JCI-S-001 [52] was used:

$$
\mathrm{G}_{\mathrm{F}, \mathrm{CMOD}}=\frac{0.75 \mathrm{~W}_{0}+\mathrm{W}_{1}}{\mathrm{~A}_{\mathrm{lig}}}
$$

where the first addend $\mathrm{W}_{0}$ represents the area below the load-CMOD curve, properly reduced by means of a correction factor 0.75 (which was derived for standard concrete elements), the second addend $\mathrm{W}_{1}$ is the work performed by the specimen self-weight and by the weight of the loading apparatus, and $\mathrm{A}_{\text {lig }}$ indicates the area of the broken ligament (equal to $\mathrm{b} \times \mathrm{h}^{*}$, where $\mathrm{h}^{*}$ is the difference between the height of the specimen and that of the notch). The applicability of this relation to AAC was checked by comparing its results with those obtained through the application of the general fracture mechanics equation:

$$
\mathrm{G}_{\mathrm{F}}=\frac{\widetilde{\mathrm{W}}_{0}+\mathrm{mg} \delta_{0}}{\mathrm{~A}_{\mathrm{lig}}}
$$

where $\widetilde{\mathrm{W}}_{0}$ is the area under the load-midspan deflection curve, properly corrected by taking into account the work performed by the self-weight and by the weight of the loading jig. In detail, $m=m_{1}+2 m_{2}$ is the sum of the mass of the beam portion within the supports 
and that of the loading apparatus directly weighing down on it, $g$ is the acceleration due to gravity and $\delta$ is the midspan deflection.

\subsection{Elastic Modulus}

The test setup up used for the determination of the elastic modulus in compression is shown in Figure 6. Before testing, samples were dried at $50 \pm 5{ }^{\circ} \mathrm{C}$ to constant mass and then left at ambient conditions for at least $5 \mathrm{~h}$. As for compressive tests, an Instron 5882 press working under loading control was used. Loading was applied perpendicularly to the direction of the rise of the AAC green cake by following the time/loading diagram suggested in RILEM Recommendations [28]. Samples were also equipped with 4 LVDTs, according to the scheme shown in Figure 6.

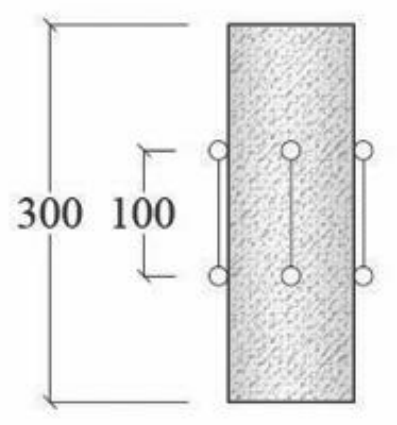

(a)

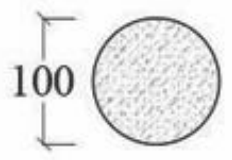

$$
\mathrm{E}_{\mathrm{c}}=\frac{\mathrm{f}_{\mathrm{a}}-\mathrm{f}_{\mathrm{b}}}{\varepsilon_{\mathrm{a}}-\varepsilon_{\mathrm{b}}}
$$

where $\mathrm{f}_{\mathrm{a}}=0.33 \mathrm{f}_{\mathrm{c}, \text { cores }} ; \mathrm{f}_{\mathrm{b}}=0.02 \mathrm{f}_{\mathrm{c}, \text { cores }} ; \mathrm{f}_{\mathrm{c}, \text { cores }}=\mathrm{F} / \mathrm{A}_{\mathrm{c}}{ }^{\prime}$ (with $\mathrm{F}$ the maximum applied load and $\mathrm{A}_{\mathrm{c}}{ }^{\prime}$ the area of the loaded surface); and $\varepsilon_{\mathrm{a}}$ and $\varepsilon_{\mathrm{b}}$ are the average values of the strains measured by the 4 LVDTs recorded under the final loading cycle at $f_{a}$ and $f_{b}$, respectively.

\section{Results and Discussion}

\subsection{Bulk Density}

The experimental results of bulk density measurements are summarized in Table 4, where they are compared with the nominal values provided by the manufacturer. A good agreement was found for all density classes, and the coefficient of variation $(\mathrm{CV}$, defined as the ratio between the standard deviation and the average value) of the experimental data was found to be always below $1 \%$. 
Table 4. Comparison between experimental results and nominal values for density.

\begin{tabular}{ccccc}
\hline Density Class & D1 & D2 & D3 & D4 \\
\hline $\begin{array}{c}\text { Nominal density }\left(\mathrm{kg} / \mathrm{m}^{3}\right) \\
\text { Average experimental }\end{array}$ & $300 \pm 50$ & $350 \pm 50$ & $480 \pm 50$ & $580 \pm 50$ \\
$\begin{array}{c}\text { density }\left(\mathrm{kg} / \mathrm{m}^{3}\right) \\
\text { CV of experimental data }(\%)\end{array}$ & 294.87 & 346.25 & 506.06 & 588.14 \\
\hline
\end{tabular}

\subsection{Compressive Strength}

The final crack pattern of AAC cubic specimens in compression is shown in Figure 7a. The Figure is relative to specimens belonging to density class D4, but a similar crack pattern was observed for all the other density classes. It can be seen that the failure mode of AAC is different from that of ordinary concrete, with the presence of irregular cracks and without a typical hourglass shape.

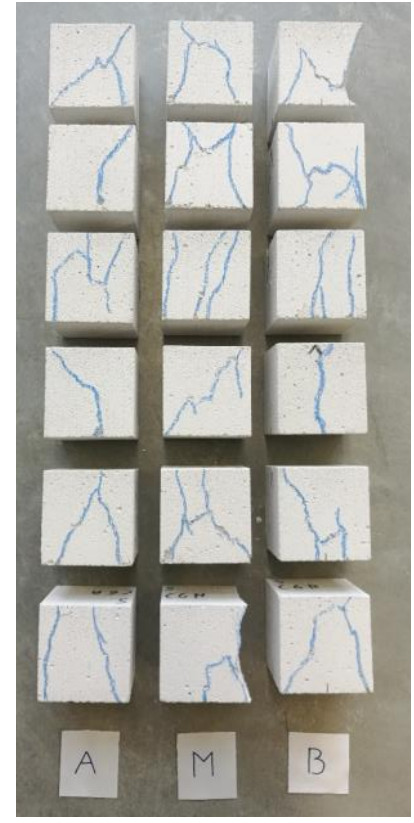

(a)

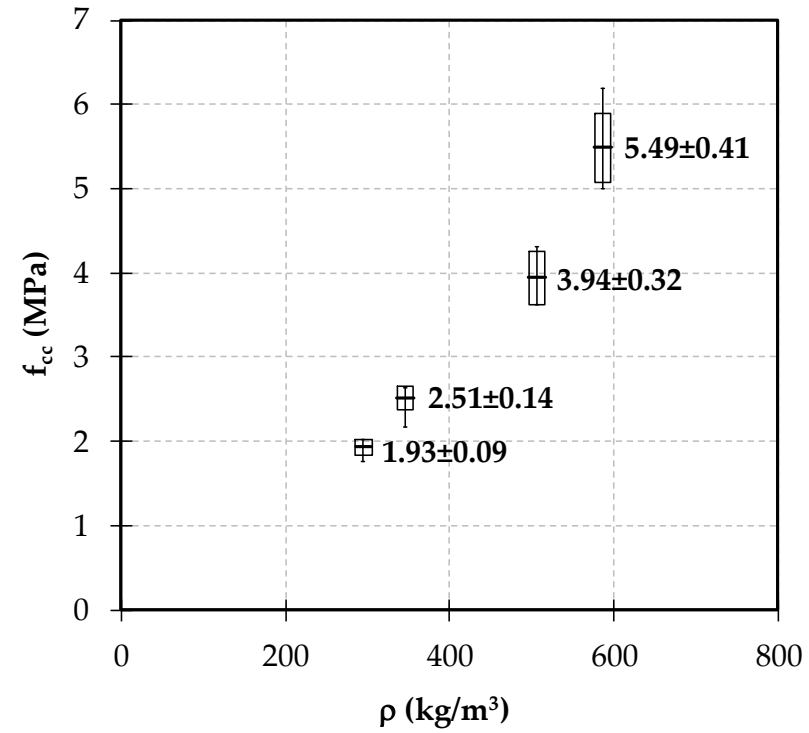

(b)

Figure 7. (a) Crack pattern at failure for specimens belonging to density class D4; (b) variation in compressive strength with density for moisture content of $\mathrm{w}_{\mathrm{s}}=(6 \pm 2) \%$. The figure also reports the average experimental value and the corresponding standard deviation.

The variation of the compressive strength with density is reported in the form of a boxplot in Figure $7 \mathrm{~b}$, with reference to a moisture content of the specimens equal to $6 \%$. For each density class, the average compressive strength and the corresponding standard deviation of the measured values are clearly indicated. The upper and lower limits of the box can be obtained by summing/subtracting the standard deviation to the mean value, while the whiskers indicate the maximum and minimum experimental values. The larger dispersion of the data referred to denser specimens is attributable to their not optimal conditioning. These specimens were indeed tested during summer, and they experienced a quicker and more pronounced drying of the external regions with respect to the inner core. The same experimental results are also rearranged in a different graphic layout in Figure $8 \mathrm{a}$, where they are compared with some empirical relations [28,31,32] and with other experimental data taken from the literature [12,27,55-57]. As can be seen, the compressive strength increases with density due to the corresponding reduction in material porosity, but the relation between the two variables is clearly nonlinear. Experimental values generally lie within the range suggested by RILEM Recommended Practice [28], which is reported 
in red in Figure 8a, and their trend is also similar to that reported in [27]. Experimental compressive strengths are higher than those predicted by the RILEM range only for density class D1, as also found in [27,32]. When comparing the data measured in this study with other available experimental results from the literature $[12,55,56]$, a greater scatter can be found. This tendency can be easily explained by taking into account the differences in raw materials (such as the inclusion of waste in the admixture) and in autoclaving process. The same graph also reports two analytical relations between compressive strength and density, derived from Chen et al. [31] (Equation (4)) and by Argudo [32] (Equation (5)) based on the results of their own experimental campaigns:

$$
\begin{aligned}
\mathrm{f}_{\mathrm{cc}} & =0.3 \mathrm{e}^{0.0043} \rho_{10 \%} \\
\mathrm{f}_{\mathrm{cc}} & =38.5 \rho_{10 \%}-790
\end{aligned}
$$

where $\rho_{10 \%}$ is the bulk density corresponding to a moisture content of $10 \%$, assuming that the ratio $\rho_{10 \%} / \rho_{\text {dry }}$ is equal to 1.1. In Equation (5), $\mathrm{f}_{\mathrm{Cc}}$ is expressed in psi, and $\rho_{10 \%}$ in pcf. These further comparisons confirm that a general relation between compressive strength and density cannot be found because the mechanical behavior of the material is strongly affected by the production process. Each relation is, therefore, simply valid for the specific product used for the calibration process. The range provided by RILEM has a general validity instead, but the compressive strength variation corresponding to each density value is quite wide, especially for denser materials.
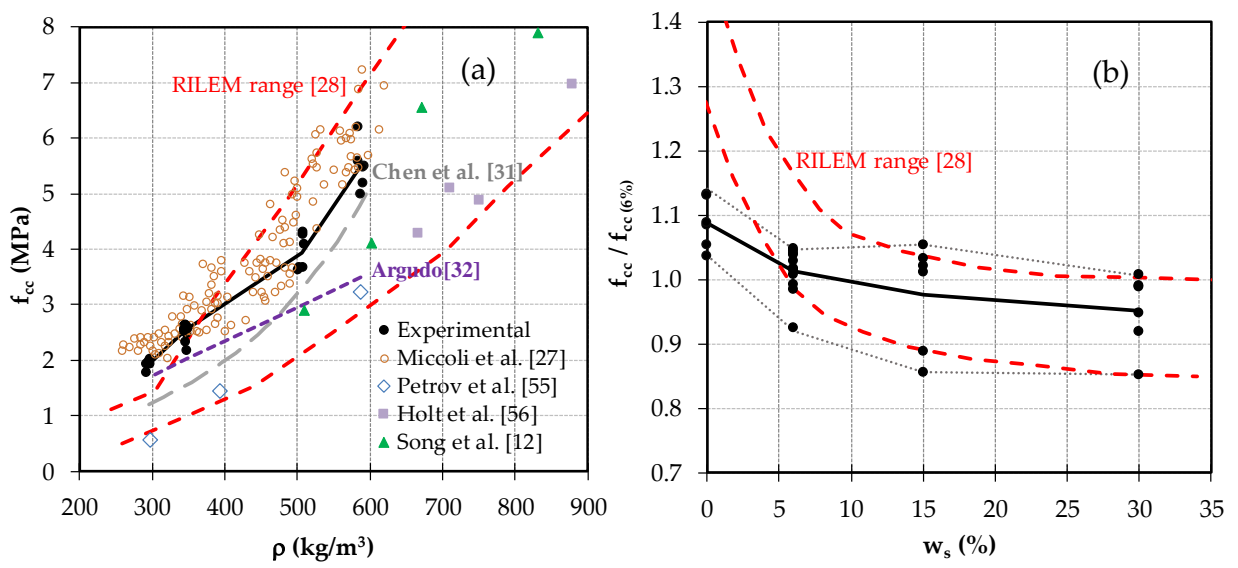

Figure 8. (a) Compressive strength vs. density: comparison between experimental results and other data from the literature RILEM Range [28] Chen et al. [31] Argudo [32] Miccoli et al. [27] Petrov et al. [55] Holt et al. [56] Song et al. [12]; (b) dimensionless compressive strength vs. moisture content RILEM Range [28].

Figure $8 \mathrm{~b}$ shows the experimental relation between the dimensionless compressive strength (normalized with respect to $\mathrm{f}_{\mathrm{cc}(6 \%)}$, corresponding to a moisture content of $6 \%$ ) and the moisture content at the time of testing for specimens belonging to density class D2. The higher investigated moisture contents, which are referred to the condition of the specimens at their delivery to the laboratory - ranging between 20 and 30\%-are herein uniformed and set equal to $30 \%$ for all the samples, to allow higher readability of the graph. The general trend observed from the experimental tests is that compressive strength is higher for lower moisture contents: passing from $\mathrm{w}_{\mathrm{s}}=6 \%$ to $\mathrm{w}_{\mathrm{S}}=0 \%$, the increase in the average compressive strength is almost equal to $8 \%$, while passing from $\mathrm{w}_{\mathrm{s}}=6 \%$ to $\mathrm{w}_{\mathrm{s}}=15 \%$ and $30 \%$, a decrease of about $2.5 \%$ and $5 \%$ can be registered, respectively. This trend is generally well documented in the literature, and this is the reason why standard codes (such as [50]) introduce a correction factor equal to 0.8 if compression tests are performed on oven-dried specimens, to take into account this increase in resistance passing from "wet state" to "dry state". 
However, the experimental increase in compressive strength in the region corresponding to moisture contents lower than $6 \%$ is less pronounced if compared to that suggested by RILEM Recommended Practice [28]. In fact, the average ratio $\mathrm{f}_{\mathrm{cc}} / \mathrm{f}_{\mathrm{cc}(6 \%)}$ for dried specimens is found to be equal to 1.09 , while the lower bound of the RILEM interval corresponds to $\mathrm{f}_{\mathrm{cc}(0 \%)} / \mathrm{f}_{\mathrm{cc}(6 \%)}=1.27$. Consequently, based on the experimental results, the correction factor suggested by the standards (equal to $1 / 1.27 \cong 0.80$ instead of $1 / 1.09 \cong 0.92$ ) seems quite punitive and could probably be slightly modified. For moisture contents higher than $6 \%$, the experimental compressive strength variation is almost superimposed with the RILEM range.

Finally, the influence of preliminary surface treatment on compressive strength is shown in Figure 9a, with reference to oven-dried specimens belonging to density class D2. The presence of a thin cardboard layer between the steel platens of the loading press and the specimen allowed the reaching of an average compressive strength $3.7 \%$ higher with respect to specimens without any surface treatment or smoothened with sandpaper, while showing a similar scattering ( $\mathrm{CV}=0.05$ and 0.04 , respectively). The use of wet surface grinding instead provided a strength increment of about $7 \%$ by reducing at the same time the scatter in the experimental measures $(\mathrm{CV}=0.02)$.
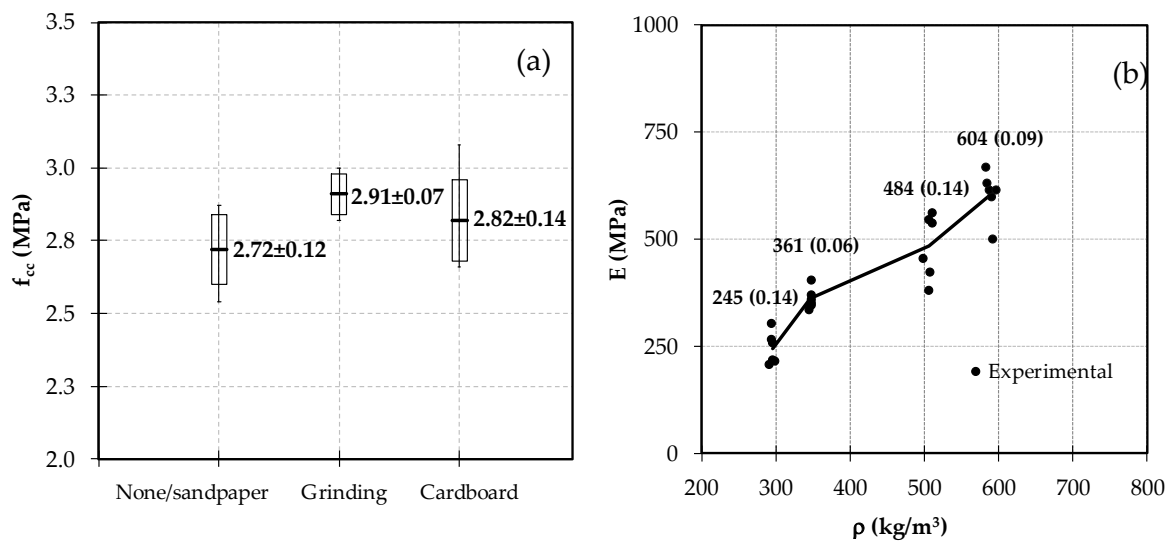

Figure 9. (a) Dependency of the compressive strength from surface treatment (for specimens belonging to D2 density class, with $\mathrm{w}_{\mathrm{S}}=0 \%$ ), and an indication of the corresponding average compressive strength and standard deviation; (b) experimental relation between elastic modulus (as derived from compression tests) and density. In this case, the average value and the coefficient of variation in the measured data (in brackets) are reported for each density class.

The experimental data collected during the experimental tests were also elaborated to determine the corresponding elastic modulus as the slope of the linear branch of the load-displacement curve in compression. Since cubic specimens were not instrumented, the displacements were assumed equal to those of the loading platens. The obtained values are reported in Figure $9 \mathrm{~b}$ as a function of material density. It can be seen that this method cannot provide a reasonable estimate of the elastic modulus (that is clearly too low) since higher deformability was found due to the initial movements between the press platens and the specimen. For this reason, it was decided to carry out specific tests (i.e., static elastic modulus tests) for the determination of this parameter, as discussed in the following sections.

\subsection{Flexural Tensile Strength}

The final crack pattern of AAC cubic specimen in bending, characterized by the presence of an almost sub-vertical crack near the midspan, is shown in Figure 10a for the tested specimens belonging to density class D1. It is worth noting that a similar crack pattern was observed for all the specimens, independently from their densities. Flexural tensile strength (modulus of rupture MOR) values are plotted as a function of density in 
Figure 10b. As can be seen, in this case, the relation between the two variables is almost linear.

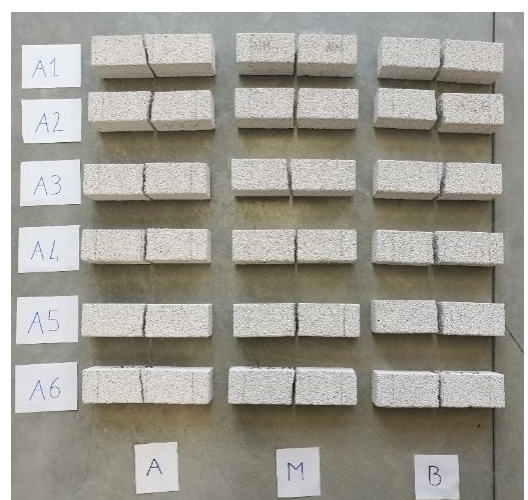

(a)

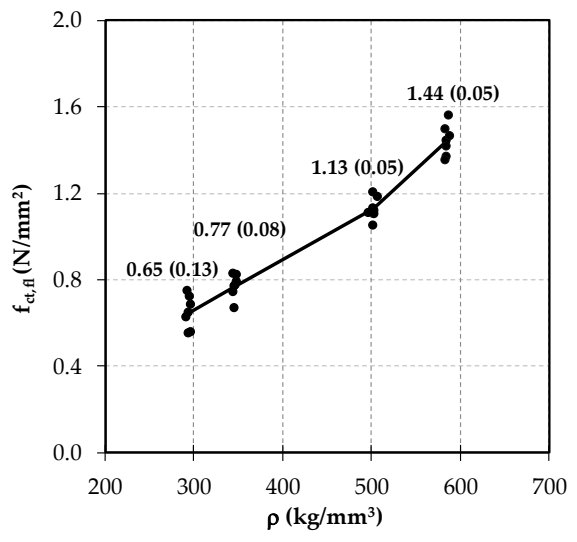

(b)

Figure 10. (a) Crack pattern at failure for specimens belonging to density class D1; (b) variation of flexural tensile strength with density, for a moisture content $\mathrm{w}_{\mathrm{S}}=(6 \pm 2) \%$, with indication of average value and the coefficient of variation in the measured data (in brackets).

However, in current practice, flexural strength is more often expressed as a function of the compressive strength rather than of the density. For this reason, the experimental relation between the two variables is plotted in Figure 11a, together with some analytical expressions taken from the literature. The relation suggested by Chen et al. (Equation (6), [31]) and by Argudo (Equation (7), [32]) are herein reported for reading convenience:

$$
\begin{gathered}
\mathrm{f}_{\mathrm{ct}, \mathrm{fl}}=0.15 \mathrm{f}_{\mathrm{cc}} \\
\mathrm{f}_{\mathrm{ct}, \mathrm{fl}}=4.8 \sqrt{f_{\mathrm{cc}}}(\mathrm{psi})
\end{gathered}
$$

as well as the linear relation suggested by RILEM [28]:

$$
\mathrm{f}_{\mathrm{ct}, \mathrm{fl}}=0.27+0.21 f_{\mathrm{cc}}
$$
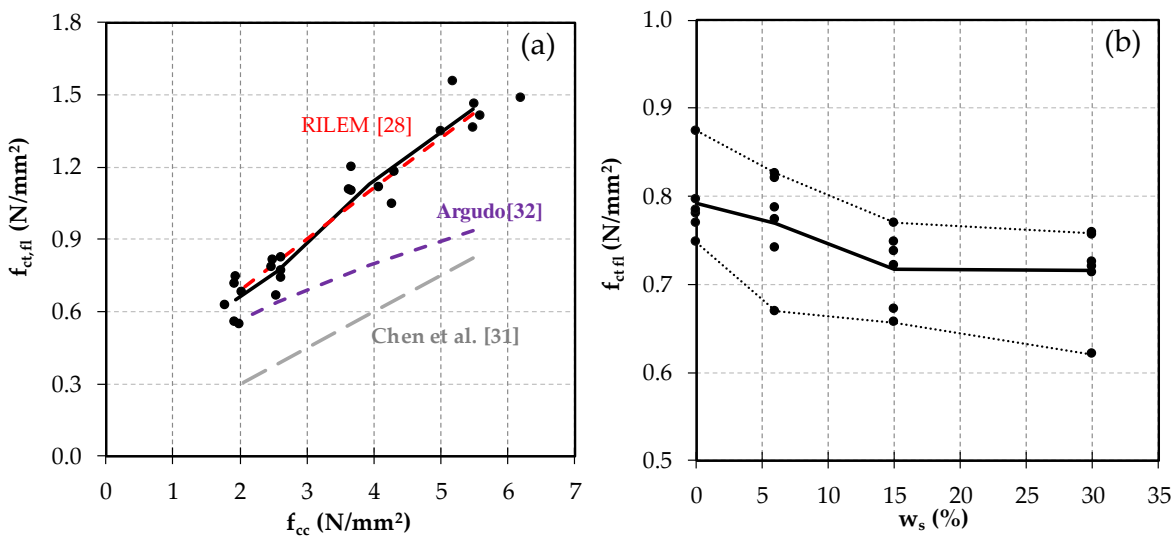

Figure 11. (a) Flexural strength vs. compressive strength for a moisture content $\mathrm{w}_{\mathrm{s}}=(6 \pm 2) \%$ RILEM [28] Argudo [32] Chen et al. [31]; (b) flexural strength vs. moisture content for density class D2.

It can be seen that RILEM relation provides a very good fit of the experimental results, also in virtue of the fact that it was calibrated on the basis of the same experimental setup (three-point bending test) and the same shear span to specimen depth ratio (equal to 1.5) 
used in the experimental campaign described in this work. The ratio between the mean value of flexural tensile strength $\mathrm{f}_{\mathrm{ct}, \mathrm{fl}}$ and the corresponding compressive strength $\mathrm{f}_{\mathrm{cc}}$ is equal to $0.34,0.31,0.29$ and 0.26 for a density class equal to D1, D2, D3 and D4, respectively. These results are quite in agreement with the findings of [28,37], where it was found that the ratio between direct tensile strength (that is generally lower than flexural strength) and compressive strength ranges between 0.15 and 0.35 . Based on previous findings of the authors [42], the ratio between direct tensile strength and flexural tensile strength can be approximately assumed equal to 0.9 .

Finally, Figure $11 \mathrm{~b}$ shows the variation in flexural strength with moisture content, with reference to specimens belonging to D2 density class. As for compressive strength, flexural strength decreases with increasing moisture content. Passing from $\mathrm{w}_{\mathrm{s}}=6 \%$ (our reference value) to $\mathrm{w}_{\mathrm{s}}=0 \%$, there is an increase in strength almost equal to $2.6 \%$, while passing from $\mathrm{w}_{\mathrm{s}}=6 \%$ to $\mathrm{w}_{\mathrm{s}}=15 \%$, a decrease of about $7 \%$ is registered. For moisture contents greater than $15 \%$, the flexural strength remains instead almost constant. The ratio

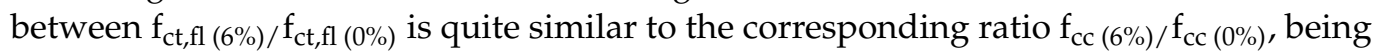
equal to 0.97 .

\subsection{Fracture Energy}

To the knowledge of the authors, a complete study reporting the variation of fracture energy with density and moisture content is not available in the literature, despite the importance of this mechanical parameter in describing the post-cracking behavior of the material. Based on the few available experimental data [39,41,42,44,58], it is generally recognized that AAC is a softening material and that the fictitious crack model used to describe the fracture process in standard concrete can also be successfully extended to the case of AAC. Material ductility can be in turn evaluated as a function of fracture energy by defining the characteristic length:

$$
1_{\mathrm{ch}}=\frac{E G_{\mathrm{F}}}{\mathrm{f}_{\mathrm{ct}}^{2}}
$$

according to $[28,41,44]$, with being $E$ the elastic modulus and $\mathrm{f}_{\mathrm{ct}}$ the direct tensile strength. Lower values of the characteristic length are associated with reduced resistance to cracking and a more brittle behavior.

As discussed in Section 2.5, in this work, fracture energy is determined following two distinct approaches, which is the one suggested by the Japanese Standard [52] based on the complete load-crack mouth opening displacement curve (Figure 12a), and the general fracture mechanics approach based on the load-midspan deflection curve. In this last case, the displacement values measured by means of LVDT and DIC are used and compared to each other (Figure 12b). The experimental results reveal that the correction factor 0.75 suggested by the Japanese Standard [52] for standard concrete to reduce the area under the load-CMOD curve can be successfully extended also to AAC. The obtained results are indeed very similar to those calculated according to Equation (2) and based on midspan deflection measurements (see Figure 12b). The experimental relation between fracture energy (calculated according to Equation (1)) and material density is found to be almost linear, as depicted in Figure 13a. For higher densities, the obtained values are similar to the average fracture energy determined in [42] within a previous experimental campaign for AAC specimens with $\rho=550 \mathrm{~kg} / \mathrm{m}^{3}$. From Figure 13b, it can also be argued that fracture properties of AAC at room temperature are not significantly affected by moisture content, as also evidenced in [44]. 

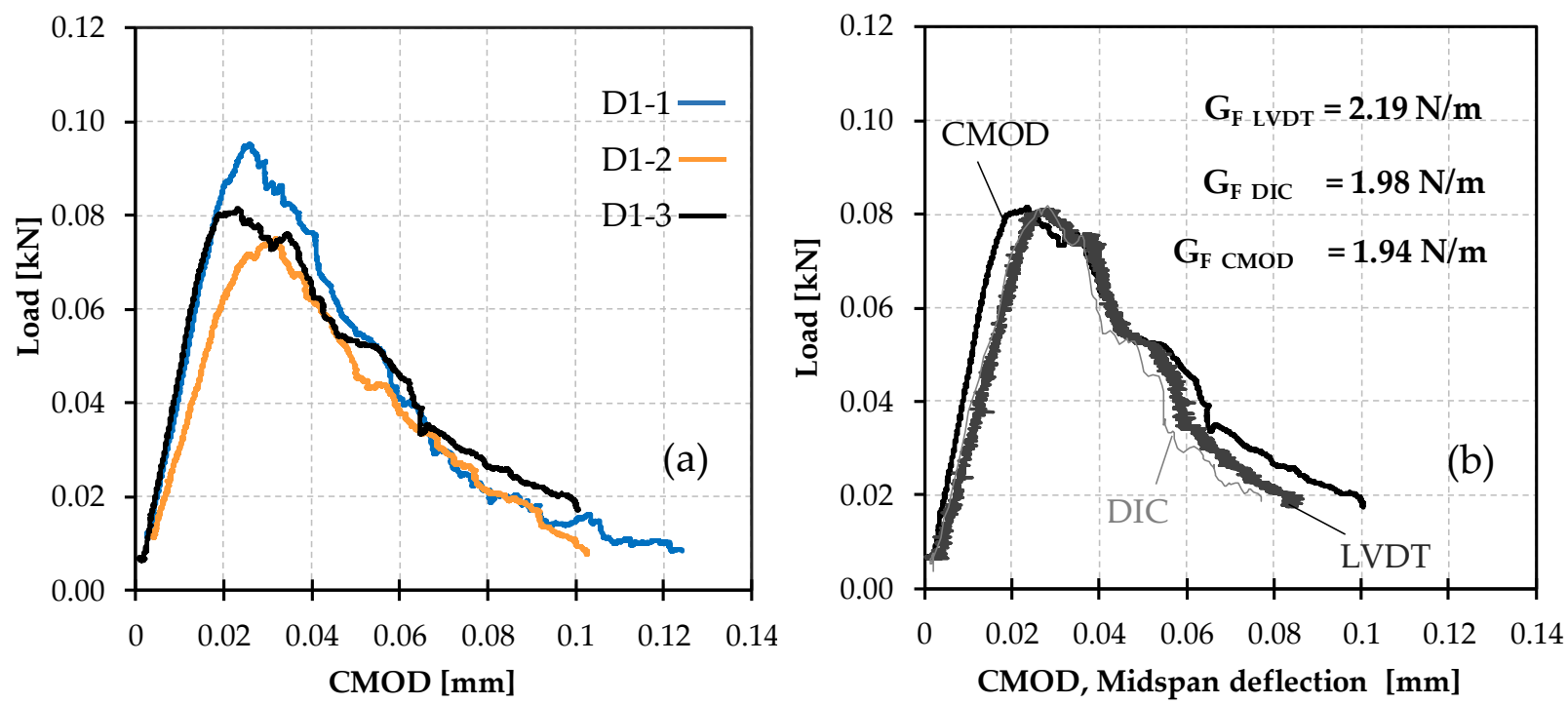

Figure 12. (a) Experimental load-CMOD curves for the 3 specimens belonging to density class D1; (b) comparison between load-CMOD curve and load-midspan deflection curves (from LVDT and DIC) for specimen D1-3. The reported GF values are calculated according Equations (1) and (2).
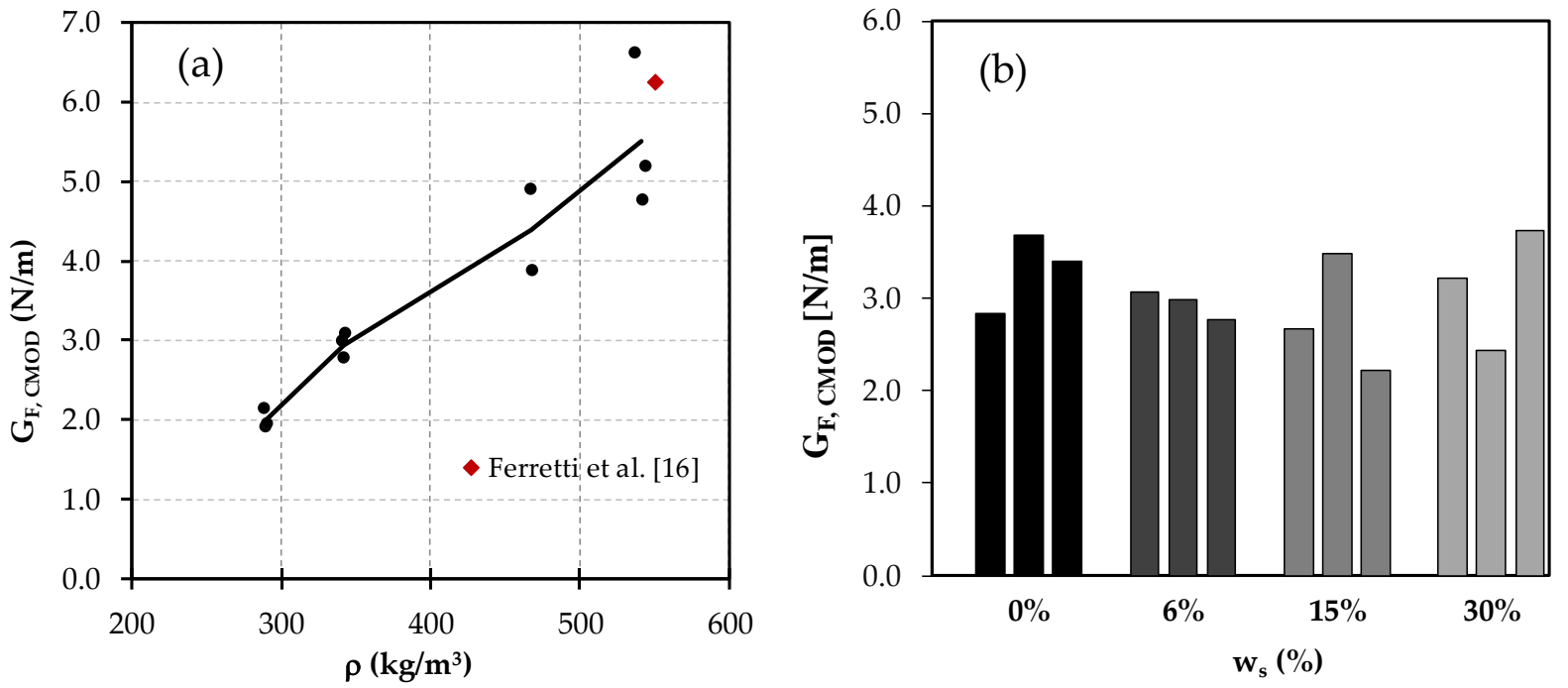

Figure 13. (a) Experimental relation between fracture energy (calculated according to Equation (1)) and material density [16]; (b) fracture energy vs. moisture content for specimens belonging to D2 density class.

\subsection{Static Modulus of Elasticity}

The experimental values of the elastic modulus in compression determined on AAC cores belonging to density classes D1 and D3 are summarized in Figure 14. The experimental values, obtained according to the procedure discussed in Section 2.6, are compared with the range of variation suggested in RILEM Recommended Practice [28], and with some analytical relation suggested in the literature [31,32], generally based on a linear regression analysis of experimental data. 

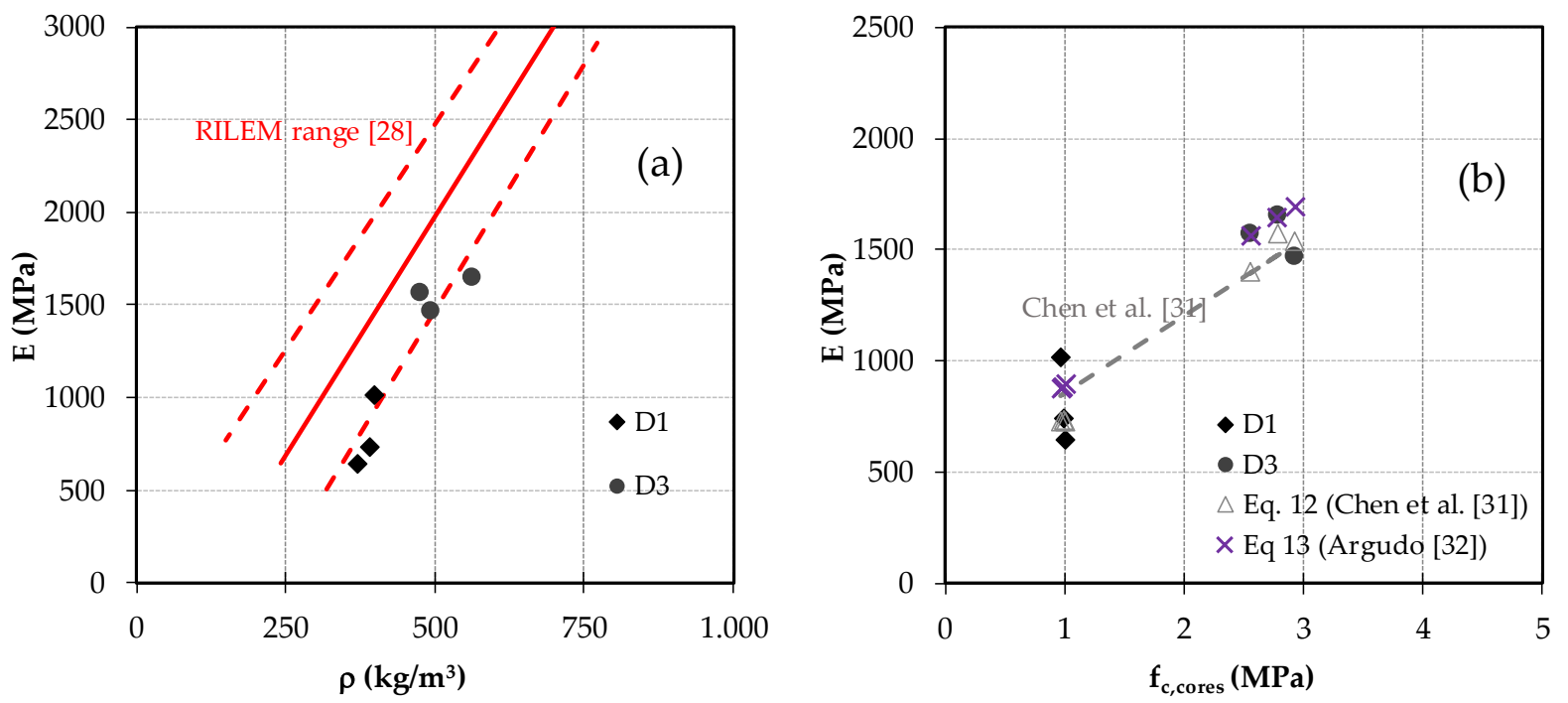

Figure 14. Experimental relation between (a) elastic modulus vs. material density RILEM Range [28]; (b) elastic modulus vs. compressive strength as determined on cores for specimens belonging to D1 and D3 density classes Chen et al. [31] Argudo [32].

The RILEM range, depicted in red in Figure 14a, is expressed through the following equation:

$$
\mathrm{E}=(-520+4.7 \rho) \pm 500 \mathrm{~N} / \mathrm{mm}^{2},
$$

while the analytical relations plotted in Figure 14b are taken from the work of Chen et al. [31] (dotted line, Equation (11); grey triangles, Equation (12)):

$$
\begin{aligned}
& \mathrm{E}=0.35 \mathrm{f}_{\mathrm{cp}}+0.5, \\
& \mathrm{E}=0.065 \rho_{10 \%}^{0.4} \mathrm{f}_{\mathrm{cp}}^{0.6},
\end{aligned}
$$

and by the work of Argudo [32] (purple cross, Equation (13)):

$$
\mathrm{E}=6500 \mathrm{f}_{\mathrm{cp}}^{0.6}(\text { in psi), }
$$

where $\mathrm{f}_{\mathrm{cp}}$ is the compressive strength measured on prisms or cores.

Comparisons highlight a reasonable fit between experimental data and all the reported analytical relations and represent further evidence that the elastic modulus should be determined based on dedicated tests, while it cannot be simply derived from standard compression tests on cubes, as already discussed in Section 3.2.

\subsection{Thermal Conductivity}

It is worth noticing that the balance between mechanical performances and environmental features of a given material can be expressed in terms of a synthetic indicator, known as "eco-mechanical index" (i.e., [48,59-61]). As for standard concrete, the mechanical performances of AAC can be expressed in terms of its compressive strength. Environmental performances can be referred to a variety of indicators related to natural resources depletion, greenhouse effect and energy consumption, etc., whose values can be deduced from Life-Cycle Assessment (LCA) studies. With respect to standard concrete, AAC building solutions are characterized by similar values of embodied energy and greenhouse emissions based on weight, but these values are significantly lower (from one-quarter to one-fifth) if they are referred to material volume, thanks to its low density. However, one of the most interesting environmental features of AAC as a building material is its thermal insulation potential, which allows a significant reduction in greenhouse emissions and energy consumption related to heating and cooling during the building life. 
Based on this observation, a possible indicator of the environmental performance of AAC can be represented by its thermal conductivity. This parameter seems more interesting with respect to thermal transmittance (that also involves additional considerations on wall thickness and stratigraphy) since it represents a material property. Thermal conductivity is strictly related to the porosity (and consequently to the density), while it seems to be much less affected by material composition (in terms of raw materials) and autoclaving process (e.g., [62]). Figure 15a shows the comparison between some experimental data available from the literature and the thermal conductivity at the dry state of the analyzed blocks declared by the producer, determined according to EN 12667 [63] by means of the guarded hot plate method. This graph highlights that thermal conductivity varies almost linearly with material density and that the scatter of data coming from different experimental campaigns $[27,62,64,65]$ is very small if compared to those data found, as shown in Figure 8a for the compressive strength. For the investigated products, the ratio between thermal conductivity to average experimental compressive strength ratio decreases almost linearly with increasing densities, ranging between 0.036 and 0.024, as plotted in Figure 15b.
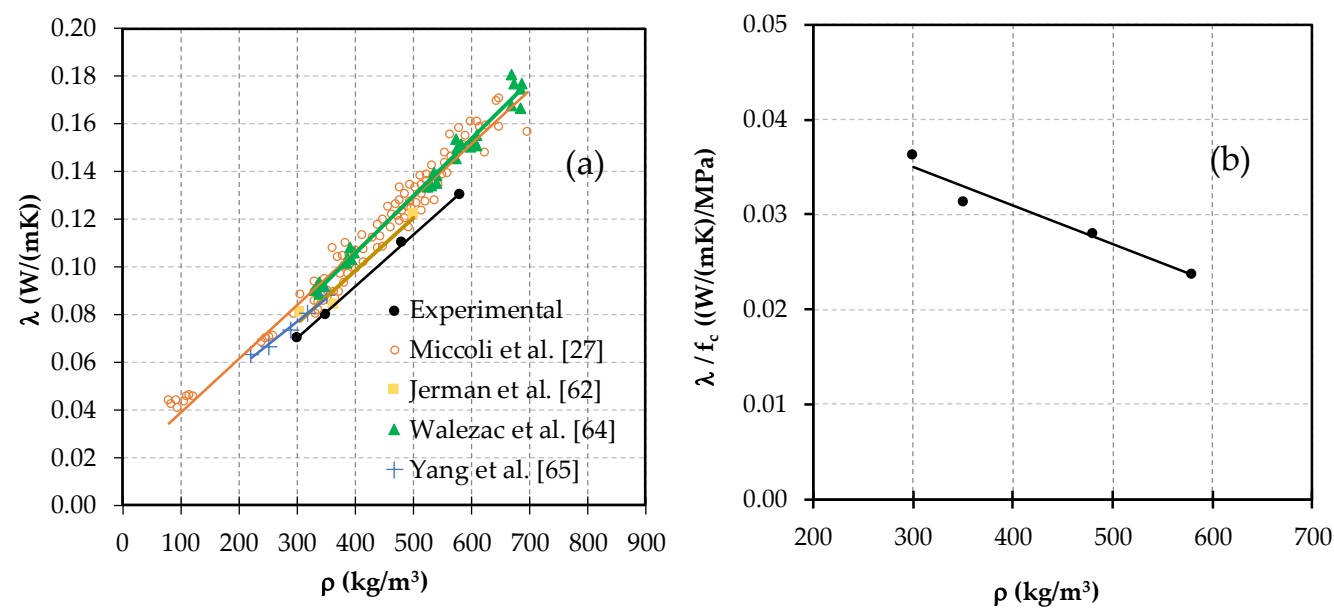

Figure 15. (a) Thermal conductivity vs. density: comparison among the data from different experimental programs Miccoli et al. [27] Jerman el al. [62] Walezac et al. [64] Yang et al. [65]; (b) Thermal conductivity to average compressive strength ratio vs. density for the 4 examined AAC products.

Eco-mechanical indexes are usually expressed in the form:

$$
\mathrm{EMI}=\frac{\mathrm{MI}}{\mathrm{EI}}
$$

where $\mathrm{MI}$ and EI are the mechanical and ecological indexes, respectively. By assuming $\mathrm{MI}=\mathrm{f}_{\mathrm{CC}}$ and $\mathrm{EI}=\lambda$, it can be seen that EMI ranges from 0.14 to $0.20,0.43$ and 0.71 for density classes D1, D2, D3 and D4 analyzed in this study, respectively. This data can be interpolated through the linear equation:

$$
\mathrm{EMI}=0.0483 \rho+13.76
$$

where $\mathrm{R}^{2}=0.97$. As already stated, the main strategy applied by AAC producers to reduce the thermal conductivity of the blocks is to reduce their density (basically acting on air pore volume, [66]), but this is in turn followed by a reduction in their compressive strength. This is an undesirable effect not only for load-bearing blocks but also for elements destined to the realization of cladding and infills since they become more prone to cracking also under service conditions, compromising the durability of the structure. The eco-mechanical index defined in Equation (14) can be used as a quick indicator to compare the performances of different AAC products belonging to a similar density class during their use phase to choose the most "efficient" product with respect to social and environmental issues (that 
is safety and energy efficiency). The challenge for researchers and producers would be to increase EMI by altering material porosity without significantly modifying the density. This result can be achieved, for example, by substituting part of the aggregate with fibers [67], or by simply using finer quartz sand and adapting the binder content to reduce the amount of residual quartz in AAC and to obtain a more homogeneous pore distribution [26]. Another possible strategy would be to make some changes to the admixture in order to increase the strength of the skeleton part. Further studies on this topic would certainly fasten the process towards the realization of NZEB buildings and the consequent reduction in the environmental impact of urbanization.

\section{Conclusions}

The increasing need to incorporate ethical aspects into the construction sector is progressively forcing the involved operators to a great change in traditional design and production approaches, passing from "old" systems merely facing mechanical issues (safety) to new systems that also incorporate environmental issues (sustainability). Within this context, modern concrete masonry blocks should ensure at the same time minimum strength requirements, together with improved thermal properties to allow a reduction in energy consumption, especially during the service life of the building. In autoclaved aerated concrete blocks, this delicate equilibrium is mainly governed by material density. This study discusses the results of a deep experimental program on the dependence of the main mechanical properties (compressive and flexural strength, fracture energy, elastic modulus) and of the thermal conductivity from material density by considering four different density classes approximately ranging from $300 \mathrm{~kg} / \mathrm{m}^{3}$ to $580 \mathrm{~kg} / \mathrm{m}^{3}$. The main findings of the study are recalled in the following:

- All the investigated properties, which are flexural tensile strength, fracture energy, elastic modulus and thermal conductivity, exhibit an almost linear dependency from density. For compressive strength, an exponential relation with density seems instead more reasonable;

- For a given density class, compressive strength values are quite dispersed since they are influenced by several intrinsic and extrinsic factors, such as the type and amount of raw materials, the autoclaving treatment and specimens' shape and dimensions. Even for a given product and a given specimen typology, the results are affected by the moisture content at the time of testing, as well as by the curing treatment before test execution. For these reasons, a relation between compressive strength and density with wide applicability can hardly be proposed. The broad range suggested by RILEM [28] confirms its validity, even if it should be revised for lower density values since the improvements in the production process progressively led to an increase in the compressive strength in time;

- Flexural tensile strength and elastic modulus show an almost linear trend with compressive strength and can be quite accurately predicted by using the analytical relations available in the literature.

The relation between fracture energy and density has been hardly studied so far; for this reason, the experimental results reported in this study can represent a useful tool for studying cracking propagation in AAC masonry, especially through FE analyses.

Environmental performances of AAC can be synthetized in terms of its thermal conductivity. Until now, this property was mainly reduced acting on material density (basically increasing air pore volume), but this, in turn, causes a reduction in the compressive strength. By assuming that the ratio between the compressive strength and the thermal conductivity can represent a sort of eco-mechanical index for AAC, further research is needed to increment this value for a given density class, through targeted modifications of the pore structure/distribution in the material or the strength of the skeleton material, without changing the amount of expansion agent. 
Author Contributions: Conceptualization, D.F. and E.M.; methodology, D.F. and E.M.; software D.F.; validation, D.F. and E.M.; formal analysis, D.F. and E.M.; investigation, D.F. and E.M.; resources, D.F.; data curation, E.M.; writing-original draft preparation, E.M.; writing—review and editing, D.F. and E.M.; visualization, D.F. and E.M.; supervision, D.F.; project administration, D.F.; funding acquisition, D.F. All authors have read and agreed to the published version of the manuscript.

Funding: This research received no external funding.

Institutional Review Board Statement: Not applicable.

Informed Consent Statement: Not applicable.

Data Availability Statement: Not applicable.

Acknowledgments: This work is part of research founded by Ekoru s.r.l., within the PON national project n. F/090017/00/X36, CUP B18I17000450008. The authors gratefully thank F. Talento, Arch. A. Riva and Eng. F. Pagliari for their valuable help.

Conflicts of Interest: The authors declare no conflict of interest.

\section{References}

1. Cordero, A.S.; Melgar, S.G.; Márquez, J.M.A. Green Building Rating Systems and the New Framework Level(s): A Critical Review of Sustainability Certification within Europe. Energies 2019, 13, 66. [CrossRef]

2. Omrany, H.; Ghaffarianhoseini, A.; Ghaffarianhoseini, A.; Raahemifar, K.; Tookey, J. Application of passive wall systems for improving the energy efficiency in buildings: A comprehensive review. Renew. Sustain. Energy Rev. 2016, 62, 1252-1269. [CrossRef]

3. Díaz, J.J.V.; Wilby, M.R.; González, A.B.R. Setting up GHG-based energy efficiency targets in buildings: The Ecolabel. Energy Policy 2013, 59, 633-642. [CrossRef]

4. European Commission. Directive 2012/27/EU of the European Parliament and of the Council of 25 October 2012 on Energy Efficiency, Amending Directives 2009/125/EC and 2010/30/EU and Repealing Directives 2004/8/EC and 2006/32/EC; European Commission: Strasbourg, France, 2012.

5. European Commission. Proposal for a Directive of the European Parliament and of the Council on Energy Efficiency (Recast); European Commission: Brussels, Belgium, 2021.

6. Konstantinou, T.; Prieto-Hoces, A. Environmental Design Principles for the Building Envelope and More: Passive and Active Measures. In Energy-Resources and Building Performance; TU Delft Open: Delft, The Netherlands, 2018; pp. 147-180. ISBN 978-94-6366-034-1.

7. Patel, J. Analyzing a Net Zero Energy Building (NZEB) in the Climate Zone of Australia. Open Sci. J. 2021, 6, 1-19. [CrossRef]

8. Trigo, T.; Flores-Colen, I.; Silva, L.; Vieira, N.; Raimundo, A.; Borsoi, G. Performance and Durability of Rendering and Basecoat Mortars for ETICS with CSA and Portland Cement. Infrastructures 2021, 6, 60. [CrossRef]

9. Koci, V.; Madera, J.; Cerny, R.; Model, A.M. Effect of Environmental Conditions on Energy Efficiency of AAC-Based Building Envelopes. Int. J. Mater. Metall. Eng. 2012, 6, 117-122.

10. Narayanan, N.; Ramamurthy, K. Microstructural investigations on aerated concrete. Cem. Concr. Res. 2000, 30, 457-464. [CrossRef]

11. Narayanan, N.; Ramamurthy, K. Structure and properties of aerated concrete: A review. Cem. Concr. Compos. 2000, 22, 321-329. [CrossRef]

12. Song, Y.; Li, B.; Yang, E.-H.; Liu, Y.; Ding, T. Feasibility study on utilization of municipal solid waste incineration bottom ash as aerating agent for the production of autoclaved aerated concrete. Cem. Concr. Compos. 2015, 56, 51-58. [CrossRef]

13. Mostafa, N. Influence of air-cooled slag on physicochemical properties of autoclaved aerated concrete. Cem. Concr. Res. 2005, 35, 1349-1357. [CrossRef]

14. Hauser, A.; Eggenberger, U.; Peters, T. Origin and characterisation of fly ashes from cellulose industries containing high proportions of free lime and anhydrite. Cem. Concr. Res. 1999, 29, 1569-1573. [CrossRef]

15. El-Didamony, H.; Amer, A.A.; Mohammed, M.S.; El-Hakim, M.A. Fabrication and properties of autoclaved aerated concrete containing agriculture and industrial solid wastes. J. Build. Eng. 2019, 22, 528-538. [CrossRef]

16. Rafiza, A.R.; Chan, H.Y.; Thongtha, A.; Jettipattaranat, W.; Lim, K.L. An innovative autoclaved aerated concrete (AAC) with recycled AAC powder for low carbon construction. IOP Conf. Ser. Earth and Environ. Sci. 2019, 268, 012050. [CrossRef]

17. Ferretti, D.; Michelini, E.; Rosati, G. Mechanical characterization of autoclaved aerated concrete masonry subjected to in-plane loading: Experimental investigation and FE modeling. Constr. Build. Mater. 2015, 98, 353-365. [CrossRef]

18. Ferretti, D.; Michelini, E.; Pongiluppi, N.; Cerioni, R. Damage Assessment of Autoclaved Aerated Concrete Buildings: Some Italian Case Studies. Int. J. Mason. Res. Innov. 2020, 5, 1. [CrossRef]

19. Woodhead Publishing. Eco-Efficient Masonry Bricks and Blocks_Design, Properties and Durability; Pacheco-Torgal, F., Lourenço, P.B., Labrincha, J.A., Kumar, S., Chindaprasirt, P., Eds.; Woodhead Publishing: Oxford, UK, 2015; ISBN 978-1-78242-305-8.

20. Radhi, H. Viability of autoclaved aerated concrete walls for the residential sector in the United Arab Emirates. Energy Build. 2011, 43, 2086-2092. [CrossRef] 
21. Hendry, E.A. Masonry walls: Materials and construction. Constr. Build. Mater. 2001, 15, 323-330. [CrossRef]

22. Drochytka, R.; Zach, J.; Korjenic, A.; Hroudová, J. Improving the energy efficiency in buildings while reducing the waste using autoclaved aerated concrete made from power industry waste. Energy Build. 2013, 58, 319-323. [CrossRef]

23. Lindberg, R.; Binamu, A.; Teikari, M. Five-year data of measured weather, energy consumption, and time-dependent temperature variations within different exterior wall structures. Energy Build. 2004, 36, 495-501. [CrossRef]

24. Paleari, M.; Miliani, A. The sustainability of wall solutions: Life Cycle Assessment (LCA) of different solutions for external closures. ce/papers 2018, 2, 489-494. [CrossRef]

25. Schöndube, T.; Rashid, S.; Carrigan, S.; Schoch, T.; Kornadt, O. Autoclaved aerated concrete: Influence of heat storage capacity on thermal performance and thermal comfort. ce/papers 2018, 2, 97-102. [CrossRef]

26. Straube, B.; Walther, H. AAC with Low Thermal Conductivity. Xella Tech. Rep. 2011, 78-80.

27. Miccoli, L.; Fontana, P.; Silva, N.; Klinge, A.; Cederqvist, C.; Kreft, O.; Qvaeschning, D.; Sjöström, C. Composite UHPC-AAC/CLC facade elements with modified interior plaster for new buildings and refurbishment. Materials and production technology. $J$. Facade Des. Eng. 2015, 3, 91-102. [CrossRef]

28. E\&FN Spon. Autoclaved Aerated Concrete-Properties, Testing and Design-RILEM Recommended Practice; Aroni, S., de Groot, G.J., Robinson, M.J., Svanholm, G., Wittman, F.H., Eds.; E\&FN Spon: London, UK, 1993; ISBN 1482271192.

29. CEN (Comitè Europèen de Normalisation). EN 1998-1: Eurocode 8-Design of Structures for Earthquake Resistance; CEN: Belgium, Brussels, 2013.

30. Bhosale, A.; Zade, N.P.; Davis, R.; Sarkar, P. Experimental Investigation of Autoclaved Aerated Concrete Masonry. J. Mater. Civ. Eng. 2019, 31, 04019109. [CrossRef]

31. Chen, Y.; Peng, M.; Zhang, Y.; Liu, Y. Mechanical Properties of Autoclaved Aerated Concrete with Different Densities. Adv. Civ. Eng. Mater. 2013, 2, 20130063. [CrossRef]

32. Argudo, J. Evaluation and Synthesis of Experimental Data for Autoclaved Aerated Concrete. Master's Thesis, The University of Texas at Austin, Austin, TX, USA, 2003.

33. Schober, G. The Most Important Aspects of Microstructure Influencing Strength of AAC; Taylor and Francis: London, UK, 2005; pp. 145-153.

34. Alexanderson, J. Relations between structure and mechanical properties of autoclaved aerated concrete. Cem. Concr. Res. 1979, 9, 507-514. [CrossRef]

35. Albayrak, M.; Yörükoğlu, A.; Karahan, S.; Atlıhan, S.; Aruntaş, H.Y.; Girgin, I. Influence of zeolite additive on properties of autoclaved aerated concrete. Build. Environ. 2007, 42, 3161-3165. [CrossRef]

36. Dembowski, J.; Fouad, F.H. Mechanical Properties of Plain AAC Material. ACI Symp. Publ. 2005, 226, 1-16. [CrossRef]

37. Valore, R.C. Cellular Concretes Part 2 Physical Properties. J. Proc. ACI 1954, 50, 817-836.

38. Hanezka, K.; Koronthalyova, O.; Matiasovskf, P. The Carbonation of Autoclaved Aerated Concrete. Cem. Concr. Res. 1997, 27, 589-599. [CrossRef]

39. Isu, N.; Teramura, S.; Ishida, H.; Mitsuda, T. Influence of quartz particle size on the chemical and mechanical properties of autoclaved aerated concrete (II) fracture toughness, strength and micropore. Cem. Concr. Res. 1995, 25, 249-254. [CrossRef]

40. Qu, X.; Zhao, X. Previous and Present Investigations on the Components, Microstructure and Main Properties of Autoclaved Aerated Concrete-A Review. Constr. Build. Mater. 2017, 135, 505-516. [CrossRef]

41. Trunk, B.; Schober, G.; Helbling, A.; Wittmann, F. Fracture mechanics parameters of autoclaved aerated concrete. Cem. Concr. Res. 1999, 29, 855-859. [CrossRef]

42. Ferretti, D.; Michelini, E.; Rosati, G. Cracking in autoclaved aerated concrete: Experimental investigation and XFEM modeling. Cem. Concr. Res. 2015, 67, 156-167. [CrossRef]

43. Wittmann, F.; Gheorghita, I. Fracture toughness of autoclaved aerated concrete. Cem. Concr. Res. 1984, 14, 369-374. [CrossRef]

44. Brühwiler, E.; Wang, J.; Wittmann, F.H. Fracture of AAC as Influenced by Specimen Dimension and Moisture. J. Mater. Civ. Eng. 1990, 2, 136-146. [CrossRef]

45. Tanner, J.E. Design Provisions for Autoclaved Aerated Concrete (AAC) Structural Systems. Ph.D. Thesis, The University of Texas at Austin, Austin, TX, USA, 2003.

46. ESR. ESR-1371 ICC ES Report-Autoclaved Aerated Concrete Block Masonry Units; ESR: Haines City, FL, USA, 2004.

47. American Concrete Institute. ACI Committee 523 Guide for Design and Construction with Autoclaved Aerated Concrete Panels; ACI 523.R4-09; American Concrete Institute: Farmington Hills, MI, USA, 2009.

48. Ferretti, D.; Gherri, B.; Michelini, E. Eco-mechanical indexes for sustainability assessment of AAC blocks. In IOP Conference Series: Materials Science and Engineering; IOP Publishing: Bristol, UK, 2018; Volume 442, p. 012011.

49. CEN (Comitè Europèen de Normalisation). EN 772-13: 2002. Methods of Test for Masonry Units_Determination of Net and Gross Dry Density of Masonry Units (Except for Natural Stone); CEN: Belgium, Brussels, 2002.

50. CEN (Comitè Europèen de Normalisation). EN 772-1: 2015. Methods of Test for Masonry Units_Part 1: Determination of Compressive Strength; CEN: Belgium, Brussels, 2015.

51. CEN (Comitè Europèen de Normalisation). EN 1351:1997: Determination of Flexural Strength of Autoclaved Aerated Concrete; CEN: Belgium, Brussels, 1997.

52. Japan Concrete Institute Standard. JCI-S-001-2003 Method of Test for Fracture Energy of Concrete by Use of Notched Beam; Japan Concrete Institute Standard: Tokyo, Japan, 2003. 
53. Mathey, R.G.; Rossiter, W.J., Jr. A Review of Autoclaved Aerated Concrete Products. NBSIR 87-3670; Research Information Center, National Bureau of Standards: Gaithersburg, MD, USA, 1988.

54. Blaber, J.; Adair, B.S.; Antoniou, A. Ncorr: Open-Source 2D Digital Image Correlation Matlab Software. Exp. Mech. 2015, 55, 1105-1122. [CrossRef]

55. Petrov, I.; Schlegel, E. Application of automatic image analysis for the investigation of autoclaved aerated concrete structure. Cem. Concr. Res. 1994, 24, 830-840. [CrossRef]

56. Holt, E.; Raivio, P. Use of gasification residues in aerated autoclaved concrete. Cem. Concr. Res. 2005, 35, 796-802. [CrossRef]

57. Rahman, R.A.; Fazlizan, A.; Asim, N.; Thongtha, A. A Review on the Utilization ofWaste Material for Autoclaved Aerated Concrete Production. J. Renew. Mater. 2021, 9, 61-72. [CrossRef]

58. Isu, N.; Teramura, S.; Ishida, H.; Mitsuda, T. Mechanical Property Evolution during Autoclaving Process of Aerated Concrete Using Slag: II, Fracture Toughness and Microstructure. J. Am. Ceram. Soc. 1994, 77, 2093-2096. [CrossRef]

59. Chiaia, B.; Fantilli, A.P.; Guerini, A.; Volpatti, G.; Zampini, D. Eco-mechanical index for structural concrete. Constr. Build. Mater. 2014, 67, 386-392. [CrossRef]

60. Hanuseac, L.; Dumitrescu, L.; Barbuta, M.; Baran, I.; Bejan, G. Eco-Mechanical Index of Lightweight Concrete Mixtures with Recycled Materials. Procedia Manuf. 2020, 46, 667-674. [CrossRef]

61. Kristiawan, S.A.; Sangadji, S. Sunarmasto Eco-durability index of self-compacting concrete incorporating high volume fly ash. In IOP Conference Series: Materials Science and Engineering; IOP Publishing: Bristol, UK, 2019; Volume 615, p. 012017.

62. Jerman, M.; Keppert, M.; Výborný, J.; Černý, R. Hygric, Thermal and Durability Properties of Autoclaved Aerated Concrete. Constr. Build. Mater. 2013, 41, 352-359. [CrossRef]

63. CEN (Comitè Europèen de Normalisation). EN 12667:2001. Thermal Performance of Building Materials and Products—Determination of Thermal Resistance by Means of Guarded Hot Plate and Heat Flow Meter Methods. Products of High and Medium Thermal Resistance; CEN: Belgium, Brussels, 2001.

64. Walczak, P.; Małolepszy, J.; Reben, M.; Szymański, P.; Rzepa, K. Utilization of Waste Glass in Autoclaved Aerated Concrete. Procedia Eng. 2015, 122, 302-309. [CrossRef]

65. Yang, R.; Zhu, J.; Wu, Z.; Wu, Z.; Li, M.; Peng, C. Thermal insulation and strength of autoclaved light concrete. J. Wuhan Univ. Technol. Sci. Ed. 2011, 26, 132-136. [CrossRef]

66. Schober, G. Porosity in Autoclaved Aerated Concrete (AAC): A Review on Pore Structure, Types of Porosity, Measurement Methods and Effects of Porosity on Properties. In Proceedings of the 5th International Conference on Autoclaved Aerated Concrete, Bydgoscsz, Poland, 14-17 September 2011; pp. 351-359.

67. Pehlivanl, Z.O.; Uzun, I.; Yücel, Z.P.; Demir, I. The effect of different fiber reinforcement on the thermal and mechanical properties of autoclaved aerated concrete. Constr. Build. Mater. 2016, 112, 325-330. [CrossRef] 